\title{
Food Proteins and Gut Mucosal Barrier. III. The Influence of Lactation and Prolactin on the in Vitro Binding and Uptake of Bovine Serum Albumin and Ovalbumin in the Rat Jejunum
}

\author{
M. STERN, P. R. HARMATZ, R. E. KLEINMAN, AND W. A. WALKER \\ Combined Pediatric Gastrointestinal and Nutrition Division, Massachusetts General Hospital, Children's \\ Hospital, Harvard Medical School, Boston, Massachusetts 02114
}

\begin{abstract}
The everted gut sac technique was used to study adaptive changes in small intestinal handling and uptake of radiolabeled bovine serum albumin and ovalbumin during lactation in rats. Binding and uptake of both proteins by the gut sacs of lactating animals were significantly less, compared to controls $(p<0.001$, after 30 min of incubation). This change was reversible after lactation ceased. The differences could not be explained by oral immunization since there were no specific antibodies found in sera, mucosal extracts, or breast milk; prior exposure to the protein did not alter the observed differences. No differences in mucosal breakdown of bovine serum albumin could be demonstrated by precipitation with trichloroacetic acid (10\%); an increase in breakdown of ovalbumin in the lactating animals was shown under the same conditions. The injection of prolactin produced differences in bovine serum albumin binding and uptake similar to the ones observed in the lactating group $(p<0.01$, after 30 min of incubation, compared to solvent-injected controls). Since food protein antigen binding, breakdown and uptake are functions of the local intestinal host defense, these findings suggest that there are adaptive changes of the gut mucosal barrier during lactation which decrease the transfer of dietary antigens from mother to infant. The adaptation of the maternal intestinal host defense was shown to be influenced by prolactin. (Pediatr Res 19: 320-324, 1985)
\end{abstract}

\section{Abbreviations}

BSA, bovine serum albumin

OVA, ovalbumin

TCA, trichloroacetic acid

Small intestinal mucosal structure and function undergo adaptive changes during lactation (1). Morphological and biochemical aspects of this adaptation have been widely investigated. An enhanced uptake of nutrients and increased activity of certain mucosal enzymes have been reported (2-6). It is not known, however, if the intestinal uptake of macromolecules $(7,8)$ also

Received July 4, 1984; accepted November 13, 1984.

Present address Dr. Martin Stern, Universitaets-Kinderklinik, Martinistrasse, 52, D-2000 Hamburg 20, Federal Republic of Germany.

Supported by grants from Deutsche Forschungsgemeinschaft, DGF Ste 305/2 1 , and from the National Institutes of Health, AM 16269, GM 21700, and HD 12437. changes during lactation. Studies into the intestinal handling and uptake of food proteins in lactating animals are of particular interest since these are maternal factors which affect the composition of milk and thereby modulate the postnatal intestinal development of suckling newborns $(9,10)$. The recent concept of an enteromammary immune system as an important part of newborn host defense against uptake of foreign antigens has been investigated mainly for its efferent components and for the specific constituents of breast milk such as secretory $\operatorname{IgA}(11)$. The afferent intestinal components of this system are less completely understood.

To study the effect of lactation on the maternal small intestinal barrier, the everted gut sac model (12) was used, as recently modified for the investigation of food protein binding, breakdown, and uptake (13). In addition, the effect of prolactin was studied (14).

\section{METHODS}

Animals. Pregnant Sprague-Dawley rats (Charles River Laboratories, Wilmington, MA) were kept on a milk and egg proteinfree Rat Chow (Ralston Purina Inc., St. Louis, MO) for at least 7 days prior to the study. None of the animals had prior exposure to OVA. After delivery, newborn animals were allowed to suckle. After 24 to $48 \mathrm{~h}$, lactating animals were sacrificed by cervical dislocation. Adult female Sprague-Dawley rats weighing between 200 to $250 \mathrm{~g}$ served as controls. In a group of the same species, $1 \mathrm{mg}$ of ovine prolactin (31 IU/mg; Sigma Chemical Co., St. Louis, MO) was injected subcutaneously, 24 and $48 \mathrm{~h}$ before the intestine was removed for incubation (15). Prolactin was dissolved in TS hormone solvent (Sigma) containing $3 \mathrm{mg}$ phenol and $50 \mathrm{mg}$ glucose per $\mathrm{ml}$ water. Control rats received injections with the solvent.

Radiolabeled proteins. BSA ( $5 \times$ crystallized; Sigma) and OVA ( $5 \times$ crystallized; Calbiochem-Behringwerke, La Jolla, CA) were found to be sufficiently pure for this study by polyacrylamide gel electrophoresis (13). BSA was labeled with $\mathrm{Na}^{125} \mathrm{I}$ (New England Nuclear, Boston, MA) according to Markwell and Fox (16). OVA was labeled with $\mathrm{Na}^{125} \mathrm{I}$ using a modified chloramine T technique (17). Free iodine was removed by gel filtration and dialysis. The specific activity was $2.5 \mu \mathrm{Ci} / \mu \mathrm{g} \mathrm{BSA}$ and $21 \mathrm{nCi} /$ $\mu \mathrm{g}$ OVA. Over $90 \%$ of the radioactivity was precipitated by $10 \%$ (w/v) TCA.

Everted gut sacs, binding, and uptake. Everted gut sacs of 5 $\mathrm{cm}$ length were prepared from proximal jejunum according to Wilson and Wiseman (12) as recently modified (13). Sacs were filled with $1 \mathrm{ml}$ and incubated in Erlenmeyer flasks containing 
$10 \mathrm{ml}$ of Tris- $\mathrm{HCl}$ buffer (30 mM, pH 7.4) with $\mathrm{NaCl} 125 \mathrm{mM}$ and fructose $10 \mathrm{mM}$. Viability of the sacs was monitored by morphology and by the active uptake of ${ }^{45} \mathrm{Ca} 0.2 \mathrm{mM}, 3-\mathrm{O}-$ [methyl- $\left.{ }^{3} \mathrm{H}\right]$-D-glucose $10 \mathrm{mM}$, and amino-cyclopentane- $1-\left[{ }^{14} \mathrm{C}\right.$ carboxylic acid] $10 \mathrm{mM}$, as described earlier (13). The final incubation fluid contained $1 \mathrm{mg} / \mathrm{ml}$ of BSA or OVA. These solutions were trace-labeled to yield $2 \times 10^{5} \mathrm{cpm} / \mathrm{ml}$. Incubations were done using a Dubnoff metabolic shaking water bath (Labline Inc., Chicago, IL) for up to $30 \mathrm{~min}$ at $37^{\circ} \mathrm{C}$ in an atmosphere of $100 \%$ oxygen. Nonspecific adsorption of protein to glass surfaces was taken into account by preincubating all incubation flasks with the labeled solutions for $30 \mathrm{~min}$, taking reference samples for specific activity before and after this preincubation. After 1 to $30 \mathrm{~min}$ of final incubation, gut sacs were removed from the flasks and blotted on filter paper. Sac contents were drained by syringe and the mucosa was scraped using glass slides. Contents and scrapings were counted separately in a Gamma 7000 counter (Beckman Instruments, Inc., Irvine, CA). Mucosal scrapings were homogenized using a Potter-Elvehjem Teflon pestle homogenizer for $5 \mathrm{~min}$ at $4^{\circ} \mathrm{C}(13)$, and their protein content was determined (18). Results for binding and uptake were calculated from the original specific activity of the solutions, corrected for nonspecific adsorption to the flasks and expressed as $\mu \mathrm{g}$ of ${ }^{125} \mathrm{I}$-labeled protein equivalents per $\mathrm{mg}$ mucosal protein (13). Uptake was defined as the amount of radioactivity found inside the gut sacs. Binding was defined as the radioactivity found in mucosal scrapings $(8,13)$.

One $\mathrm{ml}$ of the homogenized scrapings and the sac contents were subjected to precipitation by $10 \%(\mathrm{w} / \mathrm{v}) \mathrm{TCA}$ in the cold. Ten $\mu \mathrm{g}$ of cold protein were added as a carrier to the sac contents before precipitation. The amount of radioactivity precipitated was compared to the total radioactivity. In preliminary experiments $(n=8)$, there was no inhibition of TCA precipitability when cold $\mathrm{NaI}$ was added either to homogenized scrapings or to sac contents (19). The restrictions on the use of radioiodinated proteins for uptake studies which have been reported in a whole mouse system using blood samples (19) thus do not apply to the rat gut sac system. In addition, results of studies using ${ }^{14} \mathrm{C}$-labeled BSA were very similar to the ones using ${ }^{125}$ I-BSA (13).

Antibodies against $B S A$ and $O V A$. Breast milk, intestinal contents, mucosal scrapings, and sera from lactating animals and nonlactating controls were examined for the presence of antibodies to BSA and OVA by a Farr radioimmunoassay (20).

Statistical method. Student's $t$ test was used to assess statistical significance of differences between lactating animals and controls or between prolactin- and solvent-injected animals.

\section{RESULTS}

Binding and uptake of BSA in lactating animals. In preliminary experiments at $4^{\circ} \mathrm{C}$ and in experiments using sodium fluoride $1 \mathrm{mM}$ as an effective inhibitor, binding and uptake were found to be energy-dependent processes. Less BSA was bound to the jejunal mucosa of lactating rats, compared to controls (Fig. 1). Timed experiments showed that there was no further binding of BSA after $1 \mathrm{~min}$ in the lactating groups, contrary to controls. Compared to the amount bound, the amount of BSA taken up (Fig. 2) was small. Again, there was less uptake of BSA in the lactating group. The time course of BSA uptake was almost linear between 1 and $30 \mathrm{~min}$. There was no correlation found between BSA binding and uptake in lactating animals.

To determine the degree of protein breakdown, TCA precipitation studies were done. There was no significant difference in TCA precipitability between the animal groups when BSA was used (Table 1).

In two animals, the differences in BSA binding and uptake were shown to persist for 3 wk of lactation (data not shown). Two maternal rats who had been separated from their litters 12 to $24 \mathrm{~h}$ after delivery and kept single were studied for BSA uptake and binding after $3 \mathrm{wk}$. Figures for binding $(30 \mathrm{~min})$ were similar

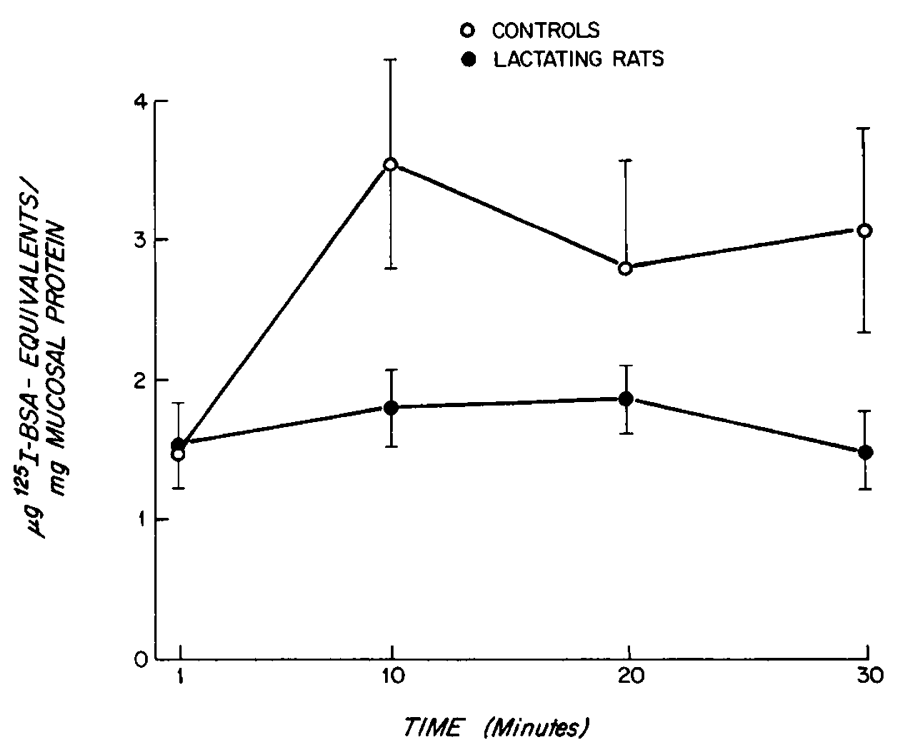

Fig. 1. Binding of ${ }^{125} \mathrm{I}-\mathrm{BSA}$ by gut sacs from lactating rats $(n=6)$ and controls $(n=6)$. Means \pm SD are given. BSA concentration $1 \mathrm{mg} / \mathrm{ml}$. Differences in binding are statistically highly significant $(p<0.001)$ after 10 and $30 \mathrm{~min}$, significant $(p<0.02)$ after $20 \mathrm{~min}$.

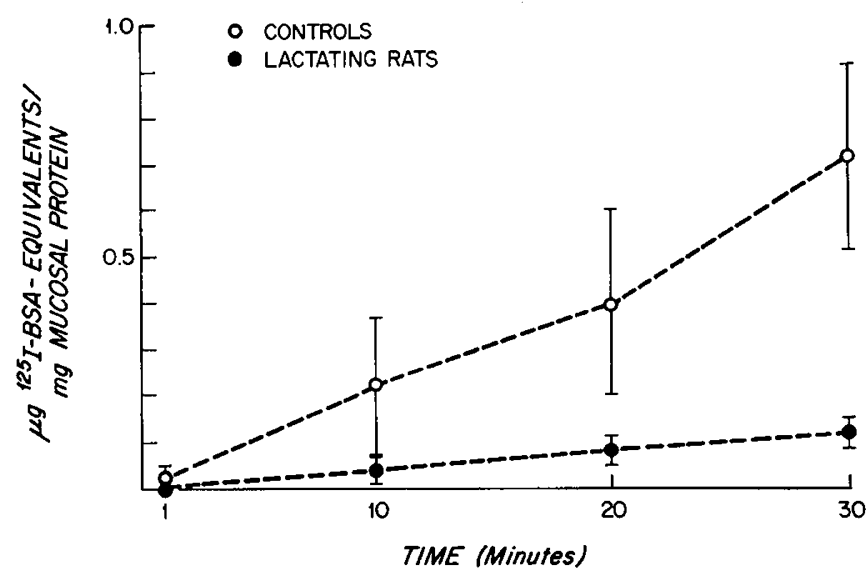

Fig. 2. Uptake of ${ }^{125}$ I-BSA by gut sacs from lactating rats $(n=6)$ and controls $(n=6)$. For details see legend Figure 1. Differences in uptake are statistically significant after $10 \mathrm{~min}(p<0.05)$ and after $20 \mathrm{~min}(p<$ $0.01)$, highly significant after $30 \mathrm{~min}(p<0.001)$.

Table 1. TCA precipitability in binding and uptake of ${ }^{125} I-B S A$ by gut sacs from lactating rats and controls*

\begin{tabular}{ccc}
\hline & $\begin{array}{c}\text { Female controls } \\
(n=6)\end{array}$ & $\begin{array}{c}\text { Lactating animals } \\
(n=6)\end{array}$ \\
\hline Binding (min) & & \\
1 & $87 \pm 4$ & $91 \pm 1 \mathrm{NS} \dagger$ \\
10 & $86 \pm 4$ & $91 \pm 2 \mathrm{NS}$ \\
20 & $88 \pm 3$ & $90 \pm 1 \mathrm{NS}$ \\
30 & $88 \pm 1$ & $89 \pm 3 \mathrm{NS}$ \\
& & \\
Uptake (min) & & \\
1 & $48 \pm 15$ & $52 \pm 4 \mathrm{NS}$ \\
10 & $40 \pm 24$ & $51 \pm 8 \mathrm{NS}$ \\
20 & $26 \pm 13$ & $35 \pm 7 \mathrm{NS}$ \\
30 & $29 \pm 11$ & $34 \pm 7 \mathrm{NS}$ \\
\hline
\end{tabular}

* Mean \pm SD, percentage TCA precipitable/total cpm.

$\dagger$ Not significant at level of $p<0.05$. 


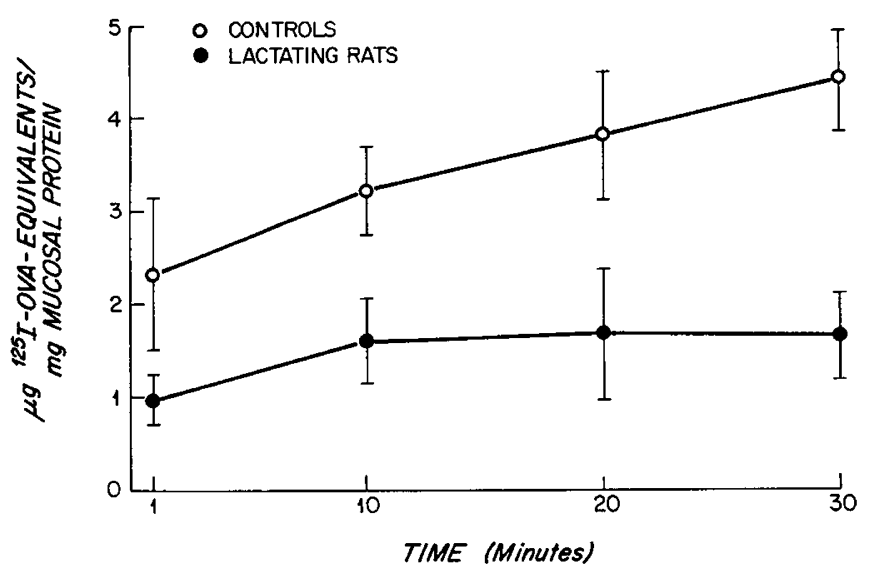

Fig. 3. Binding of ${ }^{125} \mathrm{I}$-OVA by gut sacs from lactating rats $(n=6)$ and controls $(n=6)$. For details see legend Figure 1. Differences in binding are statistically significant $(p<0.01)$ after $1 \mathrm{~min}$, highly significant $(p<0.001)$ after 10,20 , and $30 \mathrm{~min}$.

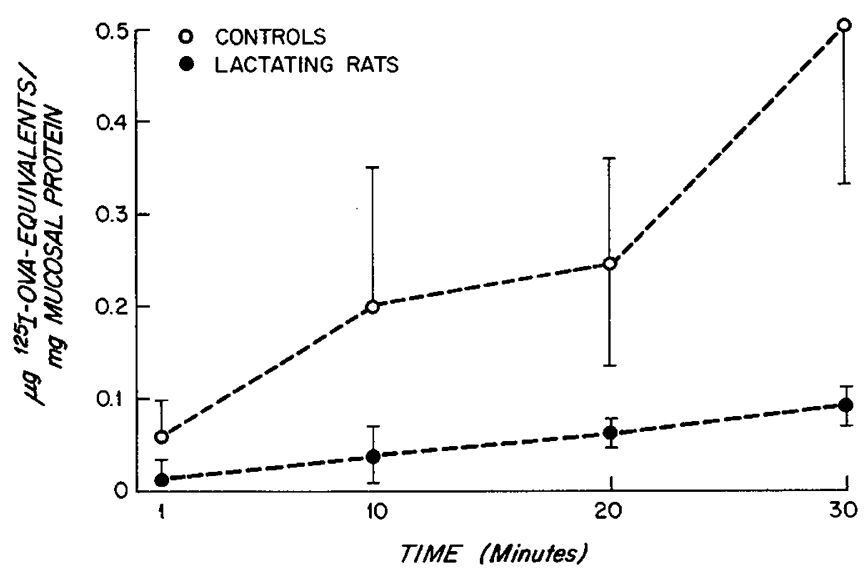

Fig. 4. Uptake of ${ }^{125} \mathrm{I}$-OVA by gut sacs from lactating rats $(n=6)$. For details see legend Figure 1 . Differences in uptake are statistically significant after 1 and $10 \min (p<0.05)$ and $20 \min (p<0.01)$, highly significant after $30 \mathrm{~min}(p<0.001)$.

to the ones obtained in the original control group of nonlactating female rats (Fig. 1). They differed from the binding figures obtained in lactating animals: $2.63 \pm 0.35(n=2)$ versus $1.48 \pm$ $0.27(n=6) \mu \mathrm{g}{ }^{125} \mathrm{I}$-BSA equivalents/mg mucosal protein, $p<$ 0.01 . The same was true for BSA uptake $(30 \mathrm{~min}): 0.20 \pm 0.06$ $\mu \mathrm{g}(n=2)$ versus $0.12 \pm 0.03 \mu \mathrm{g}(n=6), p<0.05$. Limited by the small number tested, this might indicate reversibility of the adaptive changes in BSA handling and uptake which occur during lactation.

It is possible that the pregnant animals had been fed a milkprotein containing Chow before they were purchased. In order to exclude any effect of oral immunization on food protein handling (8), separate experiments were carried out using OVA which is not present in any of the commercially available rat foods. In addition, it was shown that neither sera, breast milk, intestinal contents nor mucosal extracts from test and control animals exhibited any specific antigen binding capacity for BSA or OVA.

Differences in OVA binding and uptake in lactating animals were similar to the ones observed with BSA in that there was less binding and uptake than in the control group (Figs. 3 and 4). Contrary to BSA findings in lactating rats, OVA binding and uptake were correlated in this animal group $(r=0.87, p<0.001$, $n=24)$ and in the controls $(r=0.67, p<0.01, n=24)$. TCA precipitation studies (Table 2 ) suggested more breakdown of OVA in the lactating group, indicated by a lower percentage of
TCA precipitable radioactivity. Although this difference in TCA precipitation was not large, it was more clearly shown in the radioactivity present in mucosal scrapings than in the sac contents. Thus, less binding and uptake of OVA, a different protein the animals had never ingested, was accompanied by increased breakdown in the lactating group.

Effect of prolactin. Two consecutive daily injections of $1 \mathrm{mg}$ prolactin produced changes in BSA handling very similar to those observed in lactating rats (Table 3). The differences were most pronounced in BSA binding, but there was also less uptake in the prolactin group. Binding and uptake were correlated in this group $(r=0.68, p<0.001, n=24)$. As in the lactating animal group, there was no significant differences in TCA precipitation data between prolactin- and solvent-injected animals (data not shown). Thus, less binding and uptake of BSA by everted gut sacs could be induced in nonpregnant rats by the injection of prolactin. This change was not accompanied by changes in mucosal breakdown of BSA, as indicated by TCA precipitation.

\section{DISCUSSION}

In this study, the everted gut sac technique has been applied to look at adaptive changes in gut mucosal barrier functions

Table 2. TCA precipitability in binding and uptake of ${ }^{125} I-O V A$ by gut sacs from lactating rats and controls*

\begin{tabular}{ccc}
\hline & $\begin{array}{c}\text { Female controls } \\
(n=6)\end{array}$ & $\begin{array}{c}\text { Lactating animals } \\
(n=6)\end{array}$ \\
\hline Binding (min) & & $75 \pm 5 \dagger$ \\
1 & $84 \pm 2$ & $78 \pm 4 \ddagger$ \\
10 & $86 \pm 5$ & $78 \pm 4 \ddagger$ \\
20 & $85 \pm 4$ & $79 \pm 8 \mathrm{NS} \S$ \\
30 & $85 \pm 4$ & \\
& & \\
Uptake (min) & & $51 \pm 4 \ddagger$ \\
1 & $62 \pm 9$ & $51 \pm 10 \mathrm{NS}$ \\
10 & $57 \pm 12$ & $44 \pm 4 \mathrm{NS}$ \\
20 & $50 \pm 16$ & $41 \pm 3 \mathrm{NS}$ \\
30 & $44 \pm 10$ &
\end{tabular}

* Mean $\pm \mathrm{SD}$, percentage TCA precipitable/total cpm.

$\dagger p<0.01$.

$\ddagger p<0.05$.

$\S$ Not significant at level of $p<0.05$.

Table 3. The effect of prolactin on binding and uptake of ${ }^{125} I-$ BSA by everted gut sacs*

\begin{tabular}{ccl}
\hline & $\begin{array}{c}\text { Controls } \\
(n=7) \\
\text { solvent-injected }\end{array}$ & $\begin{array}{c}\text { Test animals } \\
(n=6) \\
\text { prolactin-injected }\end{array}$ \\
\hline Binding (min) & & \\
1 & $1.52 \pm 0.27$ & $0.96 \pm 0.33 \dagger$ \\
10 & $3.48 \pm 0.70$ & $1.03 \pm 0.35 \ddagger$ \\
20 & $2.77 \pm 0.71$ & $1.15 \pm 0.34 \ddagger$ \\
30 & $3.04 \pm 0.68$ & $1.77 \pm 0.33 \dagger$ \\
& & \\
Uptake & & \\
1 & $0.02 \pm 0.03$ & $0.03 \pm 0.02 \mathrm{NS} \S$ \\
10 & $0.20 \pm 0.15$ & $0.05 \pm 0.03 \|$ \\
20 & $0.35 \pm 0.21$ & $0.12 \pm 0.09 \|$ \\
30 & $0.62 \pm 0.29$ & $0.22 \pm 0.08 \dagger$ \\
\hline
\end{tabular}

${ }^{*}$ Mean $\pm \mathrm{SD}, \mu \mathrm{g}{ }^{125} \mathrm{I}-\mathrm{BSA}$ equivalents/mg mucosal protein.

$\dagger p<0.01$.

$\ddagger p<0.001$.

$\S$ Not significant at level of $p<0.05$.

$\| p<0.05$. 
during lactation. Binding and uptake of BSA and OVA were defined in concordance to earlier publications $(8,13)$. It has to be noted that the gut sac technique does not allow a clear-cut separation between binding to surface structures and uptake into intestinal cells. Thus, figures for radioactivity found in mucosal scrapings included material bound and material taken up into intestinal cells. The term uptake for the radioactivity on the serosal side was used as before $(8,13,21)$, although it can also be depicted as transport.

It was shown that there was less binding and uptake of BSA and OVA in the lactating animal groups, compared to controls. Except for BSA in lactating animals, the correlation between protein binding and uptake that had been shown earlier (13) was also found in this study. The changes in protein handling were unlikely to be due to an oral immunization effect (21) since there were no specific antibodies to the proteins studied in sera, secretions, and intestinal contents of the animal groups, and since the changes were observed with BSA as well as with OVA, a protein which had never been fed to the animals.

The trace-labeled protein used to investigate binding and uptake represents the original protein and its breakdown products generated by the activity of mucosa-associated enzymes ( 7 , $13,22)$. Consequently, there are no direct quantitations possible from our data on the uptake of intact BSA or OVA. Since the occurrence of foreign food protein in breast milk has been reported both in the experimental animal and in man (23), and since the absorption of antigenically intact BSA is known to be increased in suckling animals (24), changes in the intestinal handling of food antigens in lactating animals could lead to considerable changes in the degree of exposure of immature animals to foreign macromolecular antigens. In that respect, and in the context of current knowledge about the enteromammary immune system $(11,25)$, the observed changes in antigen handling during lactation appear to be part of a system which protects maternal animals and their immature suckling offspring from excessive exposure to food protein antigens. Increased mucosal protein breakdown as has been observed using TCA precipitation and the OVA label, would decrease the amount of intact food protein present at the mucous coat. In the case of BSA, a partial breakdown has been shown by gel filtration in earlier experiments (13). This partial breakdown of BSA to large fragments can not be demonstrated by the relatively rough method of TCA precipitation (Table 1).

The observed decrease in protein binding to the mucous coat of gut sacs could act as a further protective function of the gut barrier, leading to a decrease in the uptake of food proteins and their fragments that could be shown here. Mucus layer factors appear to contribute to these host defense mechanisms together with mucosa-associated proteolytic enzymes (21). It appears to be of interest in this context that decreased food protein binding and uptake were also observed in gut sacs prepared from immature suckling rats, compared to adults (26). The decreased binding in these studies depended on the presence of the mucous coat. The basic mechanisms underlying the observed changes in food protein handling and uptake during lactation remain to be clarified. Hormonally controlled changes in the fluidity or charge of the microvillus membrane (27) or the biochemical composition and viscosity of intestinal mucus (28) might influence the interaction of the small intestine and food proteins. The immunological significance of the findings reported here remains to be established. There was no evidence from our study that antigen exclusion by intestinal antibodies played any role in the groups tested, but this question awaits to be answered in more detail by our further work. It appears to be obvious from our present data that, as a sum of different events, the total amount of food protein antigenic material coming into close contact with the local immune system of lactating animals was decreased.

In the present study we also demonstrated that the changes in protein handling and uptake observed in lactating rats were reversible when lactation ceased, although the number investi- gated was low. The injection of prolactin alone, in a dose which has been shown to induce the typical changes in fluid transfer (15), caused changes very similar to those observed in the lactating group. These changes included less binding and uptake of BSA than was seen in solvent-injected control animals. Since prolactin has been reported not to be a trophic factor causing intestinal hyperplasia during lactation $(1,14)$, our findings suggest that the effect of prolactin on intestinal barrier functions is a separate and specific phenomenon. Preliminary studies currently in progress show that the changes observed occurred only during lactation and not earlier during pregnancy. The further identification of gestational and hormonal factors connected to the changes in gut barrier functions is an objective for future work. Our data suggest that the afferent intestinal component of the enteromammary immune system is subject to hormonal control. A similar control mechanism has been reported for the efferent part of this system (29). The changes in food protein handling and uptake imply an important mechanism to protect lactating animals and their suckling litters against excessive systemic food protein exposure.

\section{REFERENCES}

1. Dowling RH 1982 Small bowel adaptation and its regulation. Scand J Gastronterol Suppl 74:53-74

2. Burdett K, Reek C 1979 Adaptation of the small intestine during pregnancy and lactation in the rat. Biochem $\mathrm{J}$ 184:245-251

3. Cripps AW, Williams VJ 1975 The effect of pregnancy and lactation on food intake, gastrointestinal anatomy and the absorptive capacity of the small intestine in the albino rat. Br J Nutr 33:17-32

4. Elias E, Dowling RH 1976 The mechanism for small bowel adaptation in lactating rats. Clin Sci Mol Med 51:427-433

5. Halloran BP, DeLuca HF 1980 Calcium transport in small intestine during pregnancy and lactation. Am J Physiol 239:E64-E68

6. Palmer MF, Rolls BA 1980 Activities of some metabolic enzymes in the small intestinal mucosa during pregnancy and lactation in the rat. $J$ Reprod Fertil 60:231-236

7. Pang KY, Walker WA, Bloch KJ 1981 Intestinal uptake of macromolecules. Differences in distribution and degradation of protein antigen in control and immunised rats. Gut 22:1018-1024

8. Walker WA, Wu M, Isselbacher KJ, Bloch KJ 1975 Intestinal uptake of macromolecules. III. Studies on the mechanism by which immunization interferes with antigen uptake. J Immunol 115:854-861

9. Henning SJ 1981 Postnatal development: coordination of feeding, digestion, and metabolism. Am J Physiol 241:G199-G214

10. Lebenthal E, Lee PC 1983 Interactions of determinants in the ontogeny of the gastrointestinal tract: a unified concept. Pediatr Res 17:19-24

11. Kleinman RE, Walker WA 1979 The enteromammary immune system. An important new concept in breast milk host defense. Dig Dis Sci 24:876-882

12. Wilson TH, Wiseman G 1954 The use of sacs of everted small intestine for the study of the transference of substances from the mucosal to the serosal surface. J Physiol 123:116-125

13. Stern M, Walker WA 1984 Food proteins and gut mucosal barrier. I. Binding and uptake of cow's milk proteins by adult rat jejunum in vitro. Am J Physiol 246:G556-G562

14. Muller E, Dowling RH 1981 Prolactin and the small intestine. Effect of hyperprolactinemia on mucosal structure in the rat. Gut 22:558-565

15. Ramsey DH, Bern HA 1972 Stimulation by ovine prolactin of fluid transfer in everted sacs of rat small intestine. $J$ Endocrinol 53:453-459

16. Markwell MAK, Fox CF 1978 Surface-specific iodination of membrane proteins of viruses and eucaryotic cells using 1,3,4,6-tetrachloro-3alpha,6alphadiphenylglycoluril. Biochemistry 17:4807-4817

17. Ishizaka K, Okudaira H 1973 Reaginic antibody formation in the mouse. II. Enhancement and suppression of antihapten antibody formation by priming with carrier. J Immunol 110:1067-1076

18. Lowry OH, Rosebrough NJ, Farr AL, Randall RJ 1951 Protein measurement with the folin phenol reagent. J Biol Chem 193:262-275

19. Skogh T 1982 Overestimate of ${ }^{125}$ I-protein uptake by the adult mouse gut. Gut 23:1077-1080

20. Minden P, Farr RS 1978 Ammonium sulphate method to measure antigenbinding capacity. In: Weir EM (ed) Handbook of Experimental Immunology. Vol 1. Immunochemistry. Blackwell Scientific, Oxford, pp 13.1-22

21. Walker WA, Isselbacher KJ, Bloch NJ 1972 Intestinal uptake of macromolecules: effect of oral immunization. Science 177:608-610

22. Hemmings WA, Williams EW 1978 Transport of large breakdown products of dietary protein through the gut wall. Gut 19:715-723

23. Jakobsson I, Lindberg T 1983 Cow's milk proteins cause infantile colic in breast-fed infants: a double-blind crossover study. Pediatrics 71:268-271

24. Udall JN, Pang K, Fritze L, Kleinman R, Walker WA 1981 Development of gastrointestinal mucosal barrier. I. The effect of age on intestinal permeability to macromolecules. Pediatr Res 15:241-244

25. Udall JN, Colony P, Fritze L, Pang K, Trier JS, Walker WA 1981 Development 
of gastrointestinal mucosal barrier. II. The effect of natural versus artificial feeding on intestinal permeability to macromolecules. Pediatr Res 15:245249

26. Stern M, Pang KY, Walker WA 1984 Food proteins and gut mucosal barrier. II. Differential interaction of cow's milk proteins with the mucous coat and the surface membrane of adult and immature rat jejunum. Pediatr Res 18:1252-1257
27. Dave JR, Knazek RA, Liu SC 1981 Prolactin modifies the fluidity of rat liver membranes. Biochem Biophys Res Commun 100:45-51

28. Allen A, Bell A, Mantle M, Pearson JP 1982 The structure and physiology of gastrointestinal mucus. Adv Exp Biol Med 144:115-133

29. Lamm ME, Weisz-Carrington $P$, Roux ME, McWilliams M, Phillips-Quagliata JM 1978 Development of the IgA system in the mammary gland. Adv Exp Biol Med 107:35-42

\title{
Effect of Maternal Oxygen Inhalation on the Fetus with Growth Retardation
}

\author{
RITA A. VILEISIS \\ Department of Pediatrics, Duke University Medical Center, Durham, North Carolina 27710
}

\begin{abstract}
Decreased nutrient and oxygen transfer to the fetus accounts for fetal growth retardation in pregnancies complicated by severe uteroplacental insufficiency. $A$ model of uteroplacental insufficiency was produced by ligation of the uterine artery of one horn in pregnant rats at 17 days of gestation. The pregnant rats were assigned to environmental chambers containing a gas mixture of either an increased fractional inspired oxygen concentration of $0.40\left(\mathrm{O}_{2}\right)$ or room air from day 17 through 21 of gestation. Supplemental oxygen inhalation resulted in increased survival of the fetuses from the ligated horn [34 \pm $6 \%$ in intrauterine growth retardation (IUGR)-room air versus $57 \pm 8 \%$ in IUGR-O $\mathrm{O}_{2}$ ] and an increase in fetal weight, expressed as a percentage of nonligated appropriate for gestational age control littermates $(67 \pm 2 \%$ in IUGR-room air versus $74 \pm 2 \%$ in IUGR-O $\mathrm{O}_{2}$ ). A role for hypoxia in the suppression of fatty acid synthesis in IUGR fetal tissues had been postulated; however, maternal oxygen inhalation did not result in any increase in fatty acid content or specific activity in liver, lung, or carcass of IUGR fetuses. These data indicate that supplemental maternal oxygen inhalation improves survival and growth of fetuses compromised by uteroplacental insufficiency, but it has no apparent effect on lipogenesis at term. (Pediatr Res 19: 324-327, 1985)
\end{abstract}

\section{Abbreviations}

IUGR, intrauterine growth retardation

RA, room air

AGA, appropriate for gestational age

ip, intraperitoneal

Fetal growth is dependent on placental function, maternal nutrition, as well as many other factors. Limitation of blood flow

Received August 17, 1984; accepted November 13, 1984.

Address reprint request to R. A. Vileisis, M.D.. Duke University Medical Center, Box 3967, Durham, NC 27710.

Supported in part by the Perry Como Children's Fund, Duke University Medical Center.

This work was presented in part at the 25th Annual Meeting of the American College of Nutrition, Boston, MA, September, 1984. to the pregnant uterus restricts availability of all potential metabolic substrates to the placenta both for its own metabolic needs and for subsequent delivery to the growing fetus. Placental transfer of analogs of glucose and amino acids correlates directly with maternal placental blood flow in fetuses with spontaneous and experimentally induced growth retardation $(13,17)$. In addition, low uteroplacental blood flow results in decreased oxygen delivery to the placenta $(4,11,14)$.

Hypoxemia impairs the placenta's capacity to transfer glucose (9) and amino acids (8), thus contributing an additional mechanism for fetal growth retardation in pregnancies complicated by uteroplacental insufficiency. Furthermore, severe restriction of uterine blood flow has been shown in several animal models to result in fetal hypoxemia, and thus, contribute to growth retardation (12). The causal relationship between hypoxia and IUGR may be mediated by decreased release of growth promoting factors, and/or decreased synthetic capability due to decreased fetal oxygen consumption.

The purpose of this study was to determine the effect of increased ambient oxygen concentration in the maternal environment on the IUGR fetus. The animal model chosen was one in which all potential substrates for fetal growth were severely limited by means of uterine artery ligation, and then only one factor in the maternal environment was augmented, oxygen. Fatty acid synthesis was evaluated because it is a synthetic function that is known to be impaired in the IUGR conceptus (19), is responsive to improved nutrient availability (20), and is dependent on adequate oxygen supply (21).

\section{MATERIALS AND METHODS}

Twenty-eight pregnant Sprague-Dawley rats weighing between 250 and $325 \mathrm{~g}$ were obtained from the Charles River Laboratories (Wilmington, MA) and allowed free access to a stock diet. Rats had been mated between 19.00 and $11.00 \mathrm{~h}$. The next morning was considered to be day 0 of pregnancy. On day 17 of gestation, under ketamine anesthesia (20-30 mg, ip), a laparotomy incision was made. The uterus was exposed and a 3-0 silk ligature placed around the uterine artery supplying the uterine horn with the larger number of fetuses to produce uteroplacental insufficiency as described by Wigglesworth (23). The vasculature of the opposite uterine horn and ovarian artery of the ligated horn were left untouched. The fetuses from the nonligated horn served as 